\title{
Erratum
}

\section{Erratum: Schrode et al., Central Compensation in Auditory Brainstem after Damaging Noise Exposure}

In the article "Central Compensation in Auditory Brainstem after Damaging Noise Exposure," by Katrina M. Schrode, Michael A. Muniak, Ye-Hyun Kim, and Amanda M. Lauer, which published online on July 26, 2018, one of the funding sources listed was included erroneously. The funding listed should not have included DC009353. Additionally, an incorrect version of the Synthesis was published online. These errors do not affect the conclusions of the article. The online version has been corrected.

https://doi.org/10.1523/ENEURO.0093-19.2019 